\title{
Nodular regenerative hyperplasia of the liver, CREST syndrome and primary biliary cirrhosis: an overlap syndrome?
}

\author{
$R$ F $T$ McMAHON, C BABBS, AND $T$ W WARNES \\ From the Department of Pathology, University of Manchester, Manchester and The Liver Unit, Manchester \\ Royal Infirmary, Manchester
}

SUMMARY Nodular regenerative hyperplasia of the liver (NRHL) has been found in association with collagen vascular diseases, after drug therapy, with autoimmune disease, and with a variety of haematological disorders. The association of NRHL with the syndrome of Calcinosis cutis, Raynaud's phenomenon, oesophageal dysfunction, sclerodactyly and telangiectasia (CREST syndrome) has only been reported on two previous occasions. The liver disease usually associated with CREST syndrome is primary biliary cirrhosis (PBC) and recently nodular hyperplasia of the liver has been reported in patients with early stage PBC. We present a case of NRHL with CREST syndrome and serological and biochemical features of PBC, a newly recognised overlap syndrome.

Nodular regenerative hyperplasia of the liver (NRHL) is a rare condition in which nodules of hyperplastic hepatocytes are seen within the liver in the absence of disturbance to the architectural framework and without histological evidence of significant fibrosis or hepatocyte necrosis.' Clinically, it may be confused with cirrhosis as patients can present with the consequences of portal hypertension, liver failure and rarely, liver rupture.' The pathogenetic mechanisms involved in the development of NRHL are unknown but associations have been described with a number of collagen vascular diseases, after drug therapy, with autoimmune diseases and with a variety of haematological disorders.' The association of NRHL with the syndrome of Calcinosis cutis, Raynaud's phenomenon, oesophageal dysfunction; sclerodactyly and telangiectasia (CREST syndrome) is widely quoted but to our knowledge has been reported on only two previous occasions. ' The liver disease most frequently associated with CREST

Address for correspondence: Dr R F T McMahon. University of Manchester. Department of Pathology. Stopford Building. Oxford Road, Manchester M13 yp'T.

Accepted for publication 2S February lose. syndrome is primary biliary cirrhosis (PBC), a condition characterised by the presence of a raised serum alkaline phosphatase and antimitochondrial antibodies in serum, together with raised serum immunoglobulin $M$ levels and markedly impaired hepatic excretory capacity for the dye bromosulphthalein (BSP-K2). It has recently been suggested that nodular hyperplasia of the liver may be responsible for the development of portal hypertension in PBC of early histological stage." In this report, we present a case of CREST syndrome associated with NRHL in which there were serological and biochemical abnormalities characteristic of PBC.

\section{Case report}

A 38 year old Caucasian man was admitted in February 1988 with haematemesis and melaena. He was known to have the CREST syndrome having presented at the age of 13 years with Raynaud's phenomenon followed by cutaneous calcinosis and sclerodactyly. At the age of 23 he developed dysphagia and a barium swallow showed the typical oesophageal dysmotility of the CREST syndrome. 
During routine follow up at the age of 35 , he was found to have persistently raised serum alkaline phosphatase (ALP) and a liver biopsy was carried out at another hospital. This was initially reported to be normal. There was no previous history of liver disease and he had taken no regular medication.

Physical examination at the time of his transfer to our unit revealed the typical cutaneous features of the CREST syndrome but no stigmata of chronic liver disease. Liver function tests showed a serum aspartate transaminase of $35 \mathrm{U} / \mathrm{l}$ (normal 5-45 U/l), serum bilirubin of $18 \mu \mathrm{mol} / \mathrm{l}$ (normal $<22 \mu \mathrm{mol} / \mathrm{l})$, serum alkaline phosphatase $520 \mathrm{U} / \mathrm{l}$ (normal $<330$ $\mathrm{U} / \mathrm{l}$ ), serum albumin $38 \mathrm{~g} / \mathrm{l}$ (normal $35-45 \mathrm{~g} / \mathrm{l}$ ) and prothrombin time 18 seconds (control 15 seconds). Serum IgG and $\operatorname{IgA}$ concentrations were normal but the IgM was markedly raised at $6.6 \mathrm{~g} / \mathrm{l}$ (normal $0.5-$ $2.0 \mathrm{~g} / \mathrm{l})$. An autoantibody screen revealed the presence of anticentromere and antimitochondrial antibodies, the latter being of the naturally occurring type.' Furthermore, hepatic excretory capacity assessed by bromosulphthalein injection (BSP K2) was grossly impaired $(1 \cdot 1 \% / \mathrm{min}$ (normal $5 \cdot 5 \pm 1 \cdot 9 \%$ / $\mathrm{min})$ ) as characteristically seen in patients with PBC. ${ }^{5}$

Upper gastrointestinal endoscopy showed that the bleeding was from oesophageal varices. This was not controlled by conservative measures, however, and an emergency oesophageal transection was therefore performed. At operation the peritoneal cavity contained $3 l$ ascites, the spleen was enlarged and the liver was said to be coarse, nodular and cirrhotic; a wedge biopsy was taken for histological examination. Postoperative recovery was complicated by a subphrenic abscess and jaundice which completely resolved, although the serum alkaline phosphatase remained raised. Measurement of the wedged hepatic vein pressure was normal at less than $6 \mathrm{~mm}$ $\mathrm{Hg}$ confirming that the portal hypertension was of the presinusoidal type. He suffered no further gastrointestinal bleeds.

\section{PATHOLOGY}

The previous liver biopsy was reviewed. This showed preservation of the hepatic architecture; however, nodules of hyperplastic hepatocytes were seen, not associated with fibrosis or necrosis. There was expansion of the liver cell plates as well as nuclear pleomorphism. Nodules were best seen on the reticulin preparation (Figure) where compression of

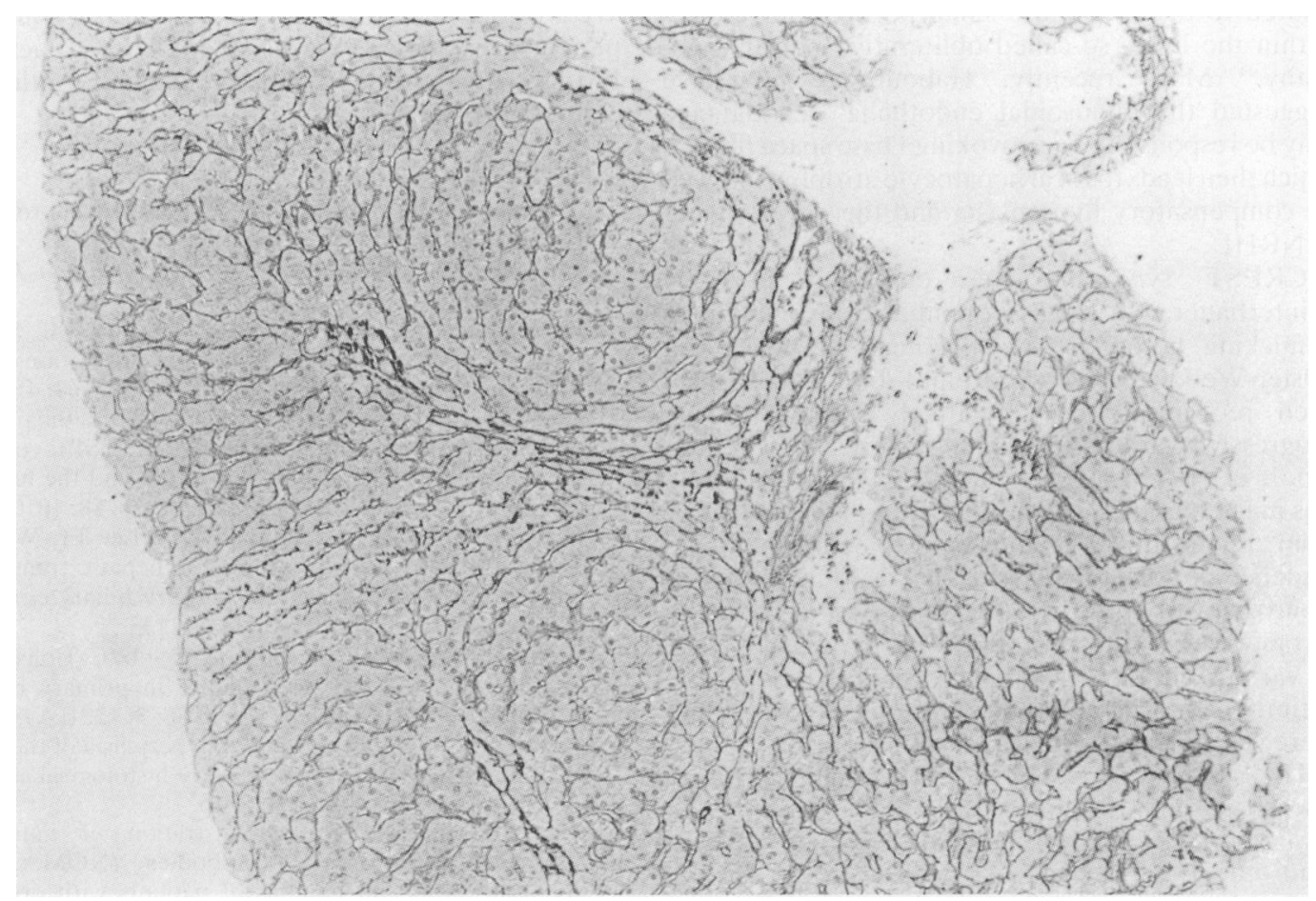

Figure Original needle biopsy showing well formed nodules in which the liver cell plates are expanded and which are bounded by compressed reticulin fibres (not fibrous tissue). (Gordon and Sweets' reticulin) 
the adjacent parenchyma and of some hepatic vein radicles, with associated sinusoidal dilatation, was also observed. Inflammatory cell infiltration was minimal and all portal tracts were normal; in particular, normal bile ducts were noted in each portal area. Somewhat surprisingly, although similar nodules were seen in the wedge biopsy specimens, the changes were rather more subtle than in the needle core. Again, no significant fibrosis, necrosis or inflammation was detected and all portal tracts contained a normal bile duct. These changes were interpreted as those of NRHL without histological evidence of PBC.

\section{Discussion}

Nodular regenerative hyperplasia of the liver has been recognised for many years under several guises including nodular transformation of the liver, ${ }^{8}$ noncirrhotic nodulation," hepatocellular adenomatosis, "' miliary hepatocellular adenomatosis" and adenomatous hyperplasia. ${ }^{12}$ In 1974 , a patient with NRH associated with Felty's syndrome was described $^{13}$ and subsequently, the condition has been reported in association with a wide range of systemic diseases. The pathogenesis of NRHL is unknown although Wanless et al have suggested that it is related to disease of the small portal vein radicles within the liver, so-called obliterative portal venopathy. ${ }^{14}$ More recently, Haboubi et al ${ }^{15}$ have suggested that sinusoidal endothelial cell damage may be responsible by provoking Disse space fibrosis which then leads to focal hepatocyte atrophy followed by compensatory hyperplasia and the development of NRHL.

CREST syndrome was described first by Winterbauer in 1964 as a combination of features mimicking hereditary haemorrhagic telangiectasia (Osler-Weber-Rendu syndrome) but it has since been recognised as a relatively benign, slowly progressive variant of systemic sclerosis. ${ }^{\text {th }}$ The first report of NRHL associated with CREST syndrome was made by Lurie et al in $1973 ;^{2}$ this patient suffered from recurrent gastrointestinal bleeding but no evidence of portal hypertension was found either at laparotomy or autopsy. A second case was added by Stromeyer and Ishak in a review of 30 cases of NRHL of various aetiologies.' In two cases in this series, antimitochondrial antibodies were positive although there was no morphological evidence of PBC.

The association of CREST syndrome with liver disease was first recognised in 1970 by Murray-Lyon et al who described two cases of PBC and CREST syndrome. ${ }^{7}$ A further six cases were added by Reynolds $e t a l^{1 \times}$ and subsequently, many individual and multiple case reports have emerged linking
CREST syndrome with PBC. Portal hypertension is an early feature in PBC, and is predominantly sinusoidal in type, being characterised by a raised wedged hepatic vein pressure. ${ }^{19}$ Nakanuma and Ohta have, however, recently described nodular hyperplasia in liver biopsies of patients with early stage PBC in the absence of other systemic disease and have suggested that this may contribute to the development of portal hypertension." It is therefore fascinating to note that although the patient presented here had a presinusoidal portal hypertension and does not fulfil the histological criteria for the diagnosis of $\mathrm{PBC}$, the presence of mitochondrial antibodies in serum coupled with the raised serum alkaline phosphatase concentration, raised serum IgM and impaired BSP excretion implies a definite overlap with the PBC syndrome.

Nodular regenerative hyperplasia of the liver usually requires a large wedge biopsy in order to establish the diagnosis. ${ }^{2 n}$ The present case, however, emphasises that the diagnosis can be made on needle biopsy. It highlights the importance of NRHL as a possible cause of portal hypertension in patients with CREST syndrome and indicates the presence of an overlap syndrome between NRHL, CREST syndrome and primary biliary cirrhosis.

We are grateful to Mr I MacLennan for referring this patient after surgery. We also thank Drs C Black and I Murray-Lyon for helpful discussion and continuing care of the patient.

\section{References}

1 Stromeyer FW, Ishak KG. Nodular transformation (nodular "regenerative" hyperplasia) of the liver - a clinicopathological study of 30 cases. Human Pathol 1981; 12: 60-71.

2 Luric B, Novis B, Bank S. Silber W. Botha JBC, Marks IN. CRST syndrome and nodular transformation of the liver - a case report. Gastroenterology 1973; 64: 457-61.

3 Hacki W, Bircher J, Preisig R. A new look at the plasma disappearance of sulfobromophthalein (BSP): correlation with the BSP transport maximum and the hepatic plasma flow in man. J Lab Clin Med 1976; 88: 1010-23.

4 O'Neill BP, Smith A, Haboubi NY, Lee FI, Warnes TW. New biochemical criteria for hepatic transplantation versus drug therapy in primary biliary cirrhosis (PBC) [Abstract]. Gut 1984: 25: A11133.

5 Warnes TW, Rowan BP, Smith A. Babbs C. Colchicine improves hepatic excretory failure in primary biliary cirrhosis [Abstract]. Hepatology 1988; 8: 1221(A).

6 Nakanuma Y. Ohta G. Nodular hyperplasia of the liver in primary biliary cirrhosis of early histological stages. Am J Gastroenterol 1987; 82: 8-10.

7 Klein R, Berg PA. Demonstration of naturally occurring mitochondrial antibodies (NOMA) by Western blotting in families of patients with primary biliary cirrhosis (PBC) [Abstract 801]. Hepatology 1988; 8: 1419 . 
8 Connolly CE. O`Brien MJ. Nodular transformation of the liver: report of a case. Human Pathol 1977; 8: 35()-2.

9 Smith JC. Non-cirrhotic nodulation of the liver. Arch Pathol Lab Med 1978; 102: 398-401.

10 Stumpf HH, Liber AF. Hepatocellular adenomatosis: report of a case with liver function studies. $A m \mathrm{~J} \mathrm{Med}$ 1954:7: 887-90.

11 Ranstrom S. Miliary hepatocellular adenomatosis. Acta Pathol Microbiol Scand 1953; 33: 22.5-9.

12 Gindhart TD, Cimis RJ, Mosenthal WT, Longnecker DS. Adenomatous hyperplasia of the liver. Arch Pathol Lab Med 1979; 103: 34-7.

13 Blendis LM, Parkinson MC. Shilkin KB. Williams R. Nodular regenerative hyperplasia of the liver in Felty's syndrome. $Q J$ Med 1974; 43: 25-32.

14 Wanless IR. Godwin TA. Allen F. Feder A. Nodular regenerative hyperplasia of the liver in haematologic disorders: a possible response to obliterative portal venopathy. A morphometric study of nine cases with an hypothesis on the pathogenesis. Medicine 1980; 59: 367-79.
15 Haboubi NY. Ali HM. Whitwell H. Ackrill P. Role of endothelial cell injury in the spectrum of azathioprineinduced liver disease after renal transplant: light microscopy and ultrastructural observations. Am J Gastroenterol 1988: 83: 256-61.

16 Winterbauer RH. Multiple telangiectasia. Raynaud's phenomenon, Sclerodactyly, and subcutancous calcinosis: a syndrome mimicking hereditary hacmorrhagic telangiectasia. Bull Johns Hopkins Hosp 1964: 114: 361-83.

17 Murray-Lyon IM. Thompson RPH. Anscll ID. Williams R. Scleroderma and primary biliary cirrhosis. $\mathrm{Br}$ Med J 1970; 3: 258-9.

18 Reynolds TB. Denison EK. Frankl H, Licherman Fl. Peters RL. Primary biliary cirrhosis with scleroderma. Raynaud's phenomenon and telangiectasia - new syndrome. Am J Med 1971; 50: 302-12.

19 Babbs C. Warnes TW. Cope V. Haboubi NY. Rowan BP. Smith A. Blecding varices - a significant problem in early biliary cirrhosis. J Hepatology 1986; 3: S1023.

20 Scheuer PJ. Liver biopsy interpretation. London: Baillière Tindall. Fourth ed 1988: 149-51. 